\title{
Marketing ambiental no Brasil: um estudo do estado da arte
} Environmental marketing in Brazil: a state of the art study Marketing ambiental en Brasil: un estudio del estado del arte

\author{
Carlos Alberto Menezes ${ }^{1}$ \\ Evandro Roberto Tagliaferro ${ }^{2}$ \\ João Alberto Campato Júnior ${ }^{3}$ \\ Roberto Andreani Júnior ${ }^{4}$
}

\begin{abstract}
${ }^{1}$ Mestre em Ciências Ambientais pela Universidade Brasil / Especialista em Marketing (ênfase em Marketing de Vendas) pela Faap - Fundação Armando Alvarez Penteado / Bacharel em Administração de Empresas pela UNIABC - Universidade do Grande ABC / Técnico Contábil pela E.E. S.G Amaral Vagner. Professor Titular da FAMA, Universidade de Mauá/SP, Brasil. E-mail: carloscapm2@gmail.com, ORCID: https://orcid.org/0000-0002-8232-0862
\end{abstract}

2 Doutor em Administração Empresarial e Comercio Internacional (ênfase em Meio ambiente, Economia, Desenvolvimento humano e Sustentabilidade) pela Universidade de Extremadura / Badajoz- Espanha, Suficiente Investigador em Administração de Empresas e Comércio Internacional pela Facultad de Ciencias Económicas y Empresariales / Badajoz- Espanha, Especialista em Engenharia Ambiental e Sanitária pela Faculdade Cândido Mendes / Rio de Janeiro- Brasil, Engenheiro Civil pela Faculdade de Engenharia de São José do Rio Preto / São Paulo- Brasil, Professor titular e pesquisador do Programa de Pós-graduação em Ciências Ambientais da Universidade Brasil. E-mail: evandro.tagliaferro@universidadebrasil.edu.br, ORCID: https://orcid.org/0000-0003-2557-031X

${ }^{3}$ Pós-Doutorados pela Universidade de São Paulo (USP), Universidade de Campinas (Unicamp), Universidade do Estado do Rio de Janeiro (UERJ) e Universidade Federal do Mato Grosso do Sul (UFMS). Doutor e Mestre em Letras pela Universidade Estadual Paulista (UNESP). Especialista em Educação. Bacharel em Letras/Tradutor. Professor Titular do Programa de Mestrado em Ciências Ambientais da Universidade Brasil- Fernandópolis, São Paulo- Brasil. E-mail: campatojr@gmail.com, ORCID: https://orcid.org/0000-0002-9026-5007

${ }^{4}$ Doutor em Produção Vegetal pela Universidade Estadual Paulista (UNESP), Mestre em Produção Vegetal pela Universidade Estadual Paulista (UNESP), Graduação em Engenharia Agronômica pela Universidade de Taubaté (UNITAU), Professor

Titular do Programa de Mestrado em Ciências Ambientais da Universidade Brasil- Fernandópolis, São Paulo, Brasil. E-mail: robertoandreani@uol.com.br, ORCID: https://orcid.org/0000-0002-0290-3356 
Resumo: O presente artigo é o resultado de uma pesquisa que aborda o estado do conhecimento das estratégias de marketing ambiental. Estudos foram realizados com o objetivo de fazer um panorama das pesquisas empíricas já realizadas, publicadas a partir do Banco de Teses da Coordenação de Aperfeiçoamento de Pessoal de Nível Superior (Capes), selecionando-se os trabalhos mais relevantes sobre o tema em questão. Os dados obtidos possibilitaram compreender como o marketing ambiental foi capaz de agregar valor às marcas, assim como apresentar algumas características dos consumidores e os métodos de conduta das empresas para que se tornem de fato "verdes". Essas estratégias foram identificadas para elevar o valor social e a rentabilidade dos produtos, por meio do marketing, de forma a equilibrar as necessidades da sociedade e a preservação do meio ambiente, contribuindo, assim, para que as ações empresariais alcancem o retorno esperado com o uso dessas estratégias.

Palavras-chave: equilíbrio sustentável; marketing verde; consumidor.

\begin{abstract}
The present article is the result of a research that approaches the state of knowledge of environmental marketing strategies in Brazil. Studies have been performed to provide an overview of the empirical research previously carried out, published by the means of the Foundation for the Coordination and Improvement of Higher Level or Education Personnel (Capes), appointing the most relevant performance on the topic at issue. The obtained data permitted to understand how environmental marketing added value to brands, as well as to recognize the profile of customers and the companies' methods of behavior so that they become genuinely "green". These strategies were identified to increase the social value and profitability of products via marketing, to balance the needs of society and environmental protection, thus contributing so that the business actions accomplish the expected return with the use of these strategies.
\end{abstract}

Keywords: sustainable balance; green marketing; consumer.

Resumen: Este artículo es el resultado de una investigación que aborda el estado del conocimiento de las estrategias de marketing ambiental en Brasil. Los estudios se han llevado a cabo con el objetivo de proporcionar una visión general de la investigación empírica ya realizada, publicada por el Banco de Tesis de la Coordinación para la Mejora del Personal de Educación Superior (Capes), seleccionando los trabajos más relevantes sobre el tema en cuestión. Los datos obtenidos permitieron comprender cómo el marketing ambiental fue capaz de agregar valor a las marcas, así como reconocer el perfil de los consumidores y los métodos de conducta de las empresas para que realmente se vuelvan "verdes". Estas estrategias fueran identificadas para aumentar el valor social y la rentabilidad de los productos, por medio del marketing, de manera a equilibrar las necesidades de la sociedad y la preservación del medio ambiente, contribuyendo, así, a las acciones comerciales para lograr el rendimiento esperado con el uso de estas estrategias.

Palabras clave: equilibrio sostenible; marketing verde; consumidor. 


\section{INTRODUÇÃO}

Com o crescimento exponencial da população, cresce também, em paralelo, o consumo de todos os tipos de insumos, desde a produção industrial até a prestação de serviços, e esses acabam gerando uma considerável concentração de resíduos, que nem sempre têm sua destinação feita de forma adequada, causando severos danos ao meio ambiente.

A conscientização e a adequação dos processos organizacionais visando à sustentabilidade por meio de estratégias de médio e longo prazo, nos processos de produção dentro da viabilidade econômica das empresas, demonstram ser possível obter uma elevada produção, de forma adequadamente sustentável, estabelecendo uma conscientização de todos os envolvidos nos processos e transmitindo seus valores para a sociedade, levando consigo a valorização da consciência ambiental.

Para isso, as empresas estão reconhecendo o apelo do mercado por produtos e estratégias ambientais, e estratégias para a sustentabilidade estão sendo desenvolvidas com essa finalidade.

O estudo se justifica pela necessidade de se estar sempre atento aos problemas ambientais e fazer parte das decisões estratégicas das organizações, contribuindo para um ambiente sustentável; as discussões em relação às questões ambientais vêm se tornado cada vez mais necessárias.

É notável uma significativa preocupação com a preservação do meio ambiente e uma visão sustentável se faz emergente, o que nos remete a uma investigação pontuada na seguinte questão: quais os benefícios do marketing ambiental diante da crise ambiental emergente em nosso contexto atual?

Observou-se que diversos autores, como Ottman (1994), Benton (1994), Wasik (1996), Wagner (1997), Polonsky e Ottman (1998), Pujari, Wright e Peattie (2003), Fuller e Ottman (2004), Bartiaux (2007), Rex e Baumann (2007), Teisl e Rubin e Noblet (2007) demonstram, em suas pesquisas, que há uma demanda crescente por produtos verdes. Assim sendo, as organizações devem estar preparadas para atender a esta demanda, vislumbrando novas oportunidades de negócios com potencial e diferencial competitivo perante o mercado, com base nas questões ambientais. 
Propõe-se o conhecimento de conceitos e o contexto das organizações na adoção de estratégias e técnicas do marketing ambiental e assuntos correlatos, em função de um novo padrão de produção que vise à sustentabilidade, reconhecendo as tendências e os rumos do marketing ambiental no Brasil, a partir de um levantamento temporal das últimas duas décadas, período de 2000-2019, a fim de identificar possíveis mudanças evolutivas na orientação do marketing ambiental.

A presente pesquisa objetivou analisar o estado da arte do marketing ambiental, convergindo para uma reflexão sobre as características dos padrões de consumo e produção, tendências da rotulagem ambiental e o papel da gestão empresarial muitas vezes desconexa com as questões ligadas à preservação dos recursos naturais e seus impactos na presente e nas futuras gerações.

Para tanto, foram trabalhados os seguintes objetivos específicos:

I. Apresentar as possíveis características dos consumidores e os novos padrões de consumo em relação à rotulagem verde.

II. Apresentar o levantamento do estado da arte sobre o marketing ambiental e teorias convergentes a ele.

Concluiu-se que o uso dessa estratégia de marketing possibilita aumentar as vendas e valorizar a marca das empresas que tratam da preservação ambiental diante da crise ambiental que se estabelece pelo mundo.

\section{REFERENCIAL TEÓRICO}

A necessidade de sustentabilidade trouxe para as mídias uma grande gama de palavras desconhecidas, que estavam restritas aos campos da química ou da biologia (RAFAEL, 2013). Sentenças como "energia limpa", "redução de resíduos", "cadeia de valor" e "risco ecológico" estão se tornando cada vez mais comuns para as pessoas, assim como "biocombustível", "bioeletricidade", "bioética", "bioenergia" e a tão propagada "biodiversidade".

Para Kotler e Armstrong (2003 apud FARO, 2013, p. 18):

[...] em decorrência dos avanços do Marketing a satisfação do consumidor começa a ser tratada como um dos mais importantes princípios da área. Nessa direção, a satisfação do consumidor tem sido investigada em diversas formas, que descrevem o comportamento 
do comprador e do consumidor nas dimensões econômicas, comportamentais, cognitivas e emocionais.

Segundo Rafael (2013), "as palavras ganharam o status ecológico com o adjetivo verde ligado a elas, fazendo surgir expressões como 'empregos verdes', 'escolas verdes', 'trabalho verde', 'marketing verde', entre outros".

O marketing ambiental pode ser visto como um grupo de políticas utilizadas estrategicamente para a comunicação, de forma a conquistar um determinado público por meio da diferenciação de seus produtos e serviços oferecidos, obtendo então o aumento na participação de mercado e firmando seu posicionamento como ecologicamente correto (ENOKI et al., 2008).

Segundo Baroto (2007, p. 13), "o marketing verde consiste, portanto, na prática de todas as ferramentas do marketing, porém, incorporando a preocupação ambiental que contribui com a conscientização da preservação".

Os quatro princípios do marketing verde são: ecologicamente correto, economicamente viável, socialmente justo e culturalmente aceito; eles representam o empenho das organizações em atender às necessidades e aos desejos dos consumidores por mais produtos que causem menor impacto ao ambiente ao longo do seu ciclo de vida, juntamente aos esforços dessas empresas em estimular a demanda desses produtos para que, consequentemente, aumentem seus lucros (MARSILI, 2000 apud STECKERT; BRIDI, 2005).

Observa-se que se trata de um conjunto de esforços que as empresas estabelecem para criar e comercializar produtos ecologicamente responsáveis e corretos em relação à natureza.

No marketing verde, os consumidores desejam encontrar a qualidade ambiental nos produtos e serviços que adquirem. Percebemos assim, que nenhum esforço por parte das empresas tem sentido, se os consumidores insistirem em continuar consumindo determinados bens que agridam a natureza (KOTLER, 2002, p. 94).

No ano de 2000, Kotler comenta que a orientação para o marketing societal, predecessor do marketing verde, surgiu a partir da necessidade de respeitar e preservar o meio ambiente, atendendo às necessidades e aos desejos do consumidor. Sua condição de existir é levar em consideração aspectos como a deterioração do meio ambiente, a escassez de recursos naturais, a fome e a miséria presentes atualmente em todo o mundo. Para os 
consumidores, fica a imagem de uma empresa de valor, preocupada com a natureza, cujos produtos se podem confiar. O marketing se torna ainda mais eficiente se os consumidores pensam que estão adquirindo produtos que contribuam para um mundo melhor, com o meio ambiente sendo preservado.

O produto verde deve ser concebido para satisfazer as necessidades de preservação ambiental na concepção de consumidores preocupados com essa questão, levando-se em conta que essa é uma necessidade secundária dos consumidores (CALOMARDE, 2000). Os consumidores procuram adquirir produtos para satisfazerem suas necessidades, e a característica de não agressão ao meio ambiente pode funcionar como um atrativo ímpar desses produtos, agregando valor e extrapolando as expectativas dos consumidores; assim, o Marketing Ambiental é de suma importância para que esses consumidores tenham conhecimento sobre a existência desses produtos sustentáveis.

Os produtos, para serem considerados verdes, devem levar em conta os seguintes critérios:

Ser capaz de diminuir problemas ambientais globais como, por exemplo, reduzir as emissões de CFC e CO2 / Eficiente em energia / Não poluente / Feito para durar ou para ser reutilizado ou reciclado / Ter o mínimo de embalagem / Fabricado de fontes renováveis / Descarte seguro / Prover informação suficiente no rótulo / Não prejudicial à saúde humana / Não conter substâncias danosas (BLAIR, 1992, p. 7).

Já Polonsky (1994) considera o marketing ambiental como as atividades desenvolvidas para gerar e facilitar quaisquer trocas com a intenção de satisfazer os desejos e as necessidades dos consumidores, desde que a satisfação de tais desejos e necessidades ocorra com o mínimo de impacto negativo sobre o meio ambiente.

Dentro desse contexto do marketing ambiental, Peattie (2005) retrata que a teoria do marketing, em geral, até então enraizada em uma perspectiva econômica e técnica, concentrava-se em trocas, produção e lucro, passando por uma evolução ao longo do tempo, até tornar-se mais "humana", chamando-se de marketing societal. Exprime o autor que marketing verde ou marketing ambiental é "O processo gerencial holístico responsável por identificar, antecipar e satisfazer as necessidades dos consumidores e da sociedade, de forma lucrativa e sustentável" (PEATTIE, 2005, p. 27), compreendendo dois 
lados que podem ocorrer de forma independente ou não: 1ำ- Usar recursos materiais a uma taxa em que os sistemas ambientais ou a atividade humana os possam repor e; 2o - Produzir poluição e resíduos a uma taxa em que possam ser absorvidos pelos sistemas ambientais sem prejudicar sua viabilidade.

Para Prakash (2002, p. 17), o marketing ambiental usa "[...] estratégias para promover produtos com base em apelos ambientais relativos a seus atributos, usa sistemas políticos e processos empregados pelas empresas para produzi-los ou vendê-los". Muitas empresas buscam trabalhar esses conceitos em desenvolvimento e sustentabilidade, voltados ao atendimento e aos anseios de seus vários stakeholders, sua percepção quanto às ações tomadas pelas organizações em relação a este tema, são os norteadores de suas ações, ativas ou reativas, quanto a esta relação do marketing, com direcionamento a estes princípios sustentáveis, pode-se promover vantagens à organização em diversas vertentes das empresas.

Na definição de Santesmases (1996, apud CALOMARDE, 2000), o conceito de marketing ambiental toma uma nova dimensão:

O marketing ecológico é um modo de conceber e executar a relação de troca, com a finalidade de que seja satisfatória para as partes que nela intervêm, a sociedade e o meio ambiente, mediante o desenvolvimento, valoração, distribuição e promoção por uma das partes de bens, serviços ou ideias que a outra parte necessita, de forma que, ajudando a conservação e melhoria do meio ambiente, contribuem ao desenvolvimento sustentável da economia e da sociedade (SANTESMASES, 1996 apud CALOMARDE, 2000, p. 22).

Calomarde (2000, p. 5) complementa o conceito, dizendo que o "marketing ecológico tem em sua conta as ações, positivas ou não, das ações empresariais sobre o meio natural", e elenca três relações entre o sistema econômico e o meio ambiente:

- O meio ambiente como fornecedor dos inputs necessários para o processo produtivo;

- O meio ambiente como fornecedor de serviços relacionados com o seu desfrute;

- O meio ambiente como depósito de resíduos gerados pelas atividades empresariais. 
O autor citado atenta para uma conscientização das empresas sobre a preservação do meio ambiente e propõe uma "cultura da permanência" como uma forma de manutenção do meio ambiente para as futuras gerações; dessa forma, diz que o papel do marketing ambiental é o de transmitir essa cultura para toda a sociedade, mostrando sua responsabilidade e amplitude. Assim, toda demanda ecologicamente correta vai diferenciar o marketing ecológico do marketing tradicional, pois trabalhará com aspirações e necessidades do consumidor que se tornou consciente dos problemas ambientais e está disposto a lutar contra eles.

Na publicidade ecológica as aspirações são coletivas e atingem a coletividade na sua principal demanda - sobrevivência. Dessa forma, ao escolher uma marca de uma empresa que informa que seus produtos são sustentáveis, o consumidor está confiando que esta empresa está contribuindo para um mundo menos desastroso, apenas adquirindo, por exemplo, uma margarina (RAFAEL, 2013, p. 39).

Costumeiramente, postula-se que a publicidade vende muito mais do que um produto, ela vende a promessa de satisfação de uma necessidade, vende possibilidades que ultrapassam o desejo de ter o próprio produto. Assim, as preferências se tornaram diferenciadas, com inclinação a produtos que respeitam a natureza e sua preservação, bem como as inovações tecnológicas propagadas pelas empresas, que são concebidas como fatores de libertação pelos quais os consumidores confiam e desejam se identificar (RESENDE, 2009).

Considerando esse ambiente receptivo, os estrategistas de marketing podem atuar de forma proativa, antecipando-se às questões ambientais, mantendo-se à frente da legislação e aproveitando as oportunidades; por exemplo: oportunidades de vantagens de custo, de diferenciação e de segmentos pouco explorados (PEATTIE, 2005).

Ottman (1994) afirma que ecoempresa é aquela que se distingue pela postura proativa em vez de reativa: que compreende bem as interdependências socioeconômicas dos intervenientes no mercado, que está orientada para o longo prazo e que não está apenas interessada na maximização dos lucros, mas procura também alcançar resultados sociais e, desta forma, pode assumir uma postura ambiental e ocupar seu espaço no crescente segmento de preservação, tão apreciado ultimamente. 
Para Motta e Oliveira, (2007), as vantagens competitivas do marketing ambiental comprovam que, se existe uma preocupação com o meio ambiente, inserindo-se no processo de decisão de compra dos consumidores, as ações de marketing ambiental podem ser um elemento de criação de valor e, consequentemente, de vantagem competitiva baseada no critério de diferenciação e apelo aos consumidores por um mundo melhor.

Cadore (2017, p. 14) define o marketing ambiental como "a construção e a manutenção de relacionamentos sustentáveis com os clientes, buscando entregar e aumentar o valor ao cliente, baseando-se nas variáveis que integram o tripé da sustentabilidade: o ambiental, o econômico e o social".

Para operacionalizar as estratégias deste marketing nas empresas, Camino (2006) sugere a gestão do mix de marketing sob a seguinte perspectiva: 1을 Desenvolvimento de produtos verdes; 2음 Distribuição com critérios verdes; 3 ㅇ Preços de produtos verdes; 4 ㅇ Promoção e publicidade verde.

As empresas e seus gestores precisam estar cientes de que o gerenciamento do marketing ambiental é necessário, mesmo que eles não estejam seguindo uma estratégia verde, pois, ainda que um bom desempenho possa não render uma vantagem competitiva, um mau desempenho pode representar uma vulnerabilidade estratégica e resultar em desvantagens (PEATTIE, 2005). Para melhor entender o conceito de produto verde, Peattie (2005) classifica os produtos verdes em duas categorias gerais: a primeira categoria de atributos é relativa aos impactos sociais e ambientais dos produtos tangíveis; a segunda categoria é relacionada com os processos pelos quais o produto é criado e com as características da empresa que o produz.

Existem processos decisórios que precisam ser levados em conta na gestão de produtos verdes, a qual, segundo Donaire (1999), deve levar em consideração também o tipo de embalagens mais adequadas ao ambiente, a distribuição sem riscos e o descarte sem resíduos.

Já Varadarajan (2000) define marketing ambiental como um conjunto de políticas, táticas e estratégias ambientais responsáveis que determinada organização realiza na área do Marketing, as quais se destinam a ganhar vantagem competitiva pela diferenciação de seus produtos em relação a seus concorrentes, em função da confiabilidade e qualidade de seus produtos. 
Observa-se que o mercado consumidor tem exigido a defesa do meio ambiente, com as questões ambientais sempre em pauta nas mídias, e tornou-se imperativo que as empresas se posicionem em favor dessa defesa para não perderem seus clientes, que hoje se preocupam com o consumo e o pós-consumo dos produtos; nessa perspectiva, as estratégias de marketing ambiental vêm ao encontro dessas empresas que se preocupam com o meio ambiente e têm responsabilidade com sua preservação, para atender a essa nova demanda do consumo, também conhecida como consumo verde ou consumerismo ambiental.

O consumismo ambiental, por sua vez, é uma mudança permanente nos valores sociais, já que os consumidores estão interessados em preservar sua qualidade de vida e o meio ambiente para si e para as futuras gerações, adequando-se a adquirir bens e serviços de empresas ambientalmente responsáveis. "O 'consumidor verde' amplia o conceito de qualidade intrínseca de um produto/serviço, incorporando a qualidade ambiental, relativa aos impactos ambientais do processo de produção, distribuição e consumo" (TAGLIAFERRO, 2000a, p. 15).

Para diminuir a distância entre discurso e a prática do marketing ambiental, em 2018 o CONAR (Conselho Nacional de Autorregulamentação Publicitária) estabeleceu algumas normas para veiculação de propagandas para quem de fato, procura comercializar produtos e/ou serviços sustentáveis; entre elas estão:

[...] veracidade - as informações veiculadas devem ser passíveis de verificação e de comprovação, via site, SAC e outros meios e materiais; exatidão e clareza - as informações devem ser precisas e expressas em linguagem compreensível, não ensejando interpretações equivocadas ou falsas conclusões; pertinência - as informações socioambientais divulgadas precisam ter nexo com a área de atuação da empresa. Também não é considerado pertinente apelo que divulgue como benefício o mero cumprimento de disposições legais que $\mathrm{o}$ anunciante tem obrigação de cumprir (CONAR, 2018, p. 4).

Segundo o órgão, as empresas que não cumprirem as normas estabelecidas ficarão sujeitas a sanções que vão de advertência até à suspensão da campanha publicitária.

Os produtos "ecologicamente corretos" carregam um selo que os identificam dessa forma; este selo garante que o produto passou por crite- 
riosa avaliação para ter o direito de vincular a sua marca essa certificação.

Em relação às certificações, destacar-se-á a série que compõe a Norma ISO 14.000, composta por um conjunto de regras que determinam os parâmetros e as diretrizes de gestão ambiental para as empresas. Pertencentes à International Organization for Standardization (ISO; em português, sigla para Organização Internacional para Padronização), tais normas foram criadas para diminuir o impacto provocado pelas empresas ao meio ambiente.

Muitas empresas utilizam recursos naturais, geram poluição ou causam danos ambientais por meio de seus processos de produção. Seguindo as normas da ISO 14.000, essas empresas podem reduzir significativamente esses danos ao meio ambiente (ANDRADE, 2012).

Quando uma empresa segue as normas e implanta os processos indicados, ela pode obter o Certificado ISO 14000. Este certificado é importante, pois atesta que a organização possui responsabilidade ambiental, valorizando assim seus produtos e marca. Para conseguir e manter o certificado ISO 14000, a empresa precisa seguir a legislação ambiental do país, treinar e qualificar os funcionários para seguirem as normas, diagnosticar os impactos ambientais que está causando e aplicar procedimentos para diminuir os danos ao meio ambiente (ANDRADE, 2012, p. 45).

Esse é, atualmente, o método mais eficaz de certificação ambiental, que marca a empresa como ecologicamente responsável, atendendo diretamente à necessidade do cliente ambientalmente consciente.

É importante destacar o conceito de economia verde, assunto de grande relevância na última grande conferência sobre o meio ambiente, a Rio+20, em julho de 2012, sendo o eixo principal dessa conferência "A Economia Verde no Contexto do Desenvolvimento Sustentável e da Erradicação da Pobreza" e "Governança Global para o Desenvolvimento Sustentável"; para alguns ambientalistas, toda a proposta da conferência em aplicar novas tecnologias, criação de empregos decentes e inclusão social pode representar mais uma maquiagem verde dentro do panorama social e econômico das sociedades, e não uma medida de fato eficaz, que represente a "Responsabilidade Social".

As ações verdes, as focadas em sustentabilidade de fato, tendem a provocar uma onda positiva de reações nos consumidores em relação aos 
produtos/marcas envolvidas. Então, observou-se que um empreendimento sustentável deve ser "ecologicamente correto, economicamente viável, socialmente justo e culturalmente aceito" (SOUZA, 2018). Uma estratégia eficaz para o alcance desses objetivos são o uso dos "7 Rs" - Repensar, Recusar, Reduzir, Reparar, Reintegrar, Reciclar, Reutilizar - e também dos "4 Ss" - Segurança, Sustentabilidade, Satisfação do Consumidor e Aceitação Social (Social Acceptance). Assim, as empresas respeitarão as limitações ambientais, tendo rentabilidade, e não agredirão a natureza (SOUZA, 2018).

Com atitudes estratégicas pautadas em todos os benefícios analisados e comentados na presente pesquisa, as empresas estarão aptas a desenvolver produtos realmente sustentáveis, sobre os quais o discurso de venda será condizente com a produção oferecida.

É necessário uma cautelosa atenção diante dos produtos que se denominam "verdes", pois existem muitas empresas que discursam sobre sustentabilidade, comercializam produtos "ditos ecologicamente corretos", porém a realidade de suas produções ficam longe de serem sustentáveis; essas empresas usam do marketing ambiental como uma camuflagem para vender mais e valorar suas marcas, contudo suas ações denigrem outras que agem corretamente. Essa ação "oportunista" é conhecida como greenwashing. A tradução para essa palavra é "lavagem verde", o que já expressa bem seu sentido.

O termo refere-se a informações de uma determinada empresa que não condizem com a realidade prática, ou seja, enganam os consumidores; greenwashing (do inglês green, verde, e whitewash, branquear ou encobrir) ou banho verde indica a injustificada apropriação de virtudes ambientalistas por parte de organizações (empresas, governos etc.) ou pessoas, mediante o uso de técnicas de marketing e relações públicas (E-CYCLE, 2019).

Um exemplo dessa ação, sem expor marcas, de acordo com E-CYCLE (2019), pode ser encontrado na embalagem de um sabão em pó, que se apropria do nome de uma importante floresta brasileira e se intitula como sabão em pó ecológico, apresentando uma embalagem com vários tons de verde. O fabricante certamente comete o pecado da falta de prova, pois não apresenta nenhum tipo de comprovação para se nomear ecológico. No website da marca, existe a informação de que todos os seus produtos 
são 100\% biodegradáveis e que possuem como princípio ativo ingredientes naturais. A questão é saber se o produto é natural ou se é à base de ingredientes naturais. O fabricante não se torna claro em relação a esses aspectos.

Trata-se de uma postura contraditória em relação ao discurso e à aplicação do marketing ambiental, desrespeitando os consumidores com propagandas enganosas, negligenciando sua confiança e, consequentemente, perdendo a credibilidade que possa ter construído.

Os consumidores podem averiguar a veracidade dos "produtos verdes" analisando o histórico das empresas, se essas são certificadas para comercializarem tais produtos; a auditoria de qualidade se demonstra uma das maneiras mais eficazes contra o greenwashing.

A "camuflagem verde" é definida por Martins (2018):

[...] as empresas apresentam seus produtos como se eles fossem ambientalmente corretos, sustentáveis e ecológicos, quando na verdade não são. Consiste na produção de falsa rotulagem ambiental e também na divulgação de campanhas publicitárias para construir uma imagem ecologicamente correta para seus processos antiéticos (MARTINS, 2018, p. 3).

Os consumidores de produtos considerados "verdes" se preocupam, cada vez mais, em averiguar a veracidade do que lhes são apresentados. Por esse motivo, tais pessoas já estão mais adaptadas a averiguar se os produtos considerados "verdes" realmente são o que dizem e, na dúvida quanto à sua veracidade, recorrem ao reconhecimento dos selos e das certificações:

Questione se a organização está apresentando uma solução pontual para determinada questão ambiental como, por exemplo, um produto cosmético que se diz natural, "ecológico" e preocupado com a preservação da natureza, mas que vem em uma embalagem plástica comum. Lembre-se que, quando falamos de qualidade de vida e de preservação ambiental, um processo depende do outro e nada está separado, portanto, o produto, por ser natural, não está livre de nos impactar negativamente com a sua embalagem plástica ocupando espaço por centenas de anos até ser degradado (E-CYCLE, 2019, s. p.).

Então, compreende-se que inserir o marketing ambiental no planejamento é fundamental, e colocá-lo em prática é o que realmente garantirá a credibilidade das empresas. 


\section{METODOLOGIA}

A pesquisa apresenta um estudo bibliográfico, de natureza exploratória, descritiva e qualitativa, que se pautou no levantamento de dados sobre o marketing ambiental e seus benefícios, buscando verificar o estado do conhecimento atual sobre essa temática, por meio da coleta de dados, seguida da descrição desses, mediante procedimentos específicos, escolhidos e qualificados pelo pesquisador, que, segundo Ferreira (2002), objetiva sustentar os benefícios do fenômeno investigado, com as análises de estudiosos a respeito do tema.

Para atender o objetivo da investigação, realizou-se uma busca nos principais periódicos de administração e ciências ambientais do Brasil, com vistas ao estudo do estado da arte, por meio de levantamento on-line no banco de dados da Biblioteca Digital Brasileira de Teses e Dissertações (BDTD), Google Acadêmico, Domínio Público, SciELO e outras fontes correlatas, utilizando os mecanismos de filtragem por meio do assunto "marketing ambiental e marketing verde", referente ao período de janeiro de 2000 a dezembro de 2019. Após isso, foram selecionados os trabalhos que apresentaram a referida palavra-chave para a análise de seus conteúdos.

Nessa busca, foram identificadas as tendências e os rumos do marketing ambiental no Brasil do século XXI, capazes de agregar valor às marcas, assim como reconhecer o perfil dos consumidores e os métodos de conduta das empresas para que se tornem, de fato, "verdes".

Mais de 1.000 trabalhos foram encontrados em todas as áreas de conhecimento. Redefinindo a filtragem para as áreas de Ciências Ambientais e Administração, foram identificados 283 trabalhos. Após leitura e interpretação dos temas, a princípio pelos títulos de maior relevância, fazendo, em seguida, a leitura dos resumos e refinando a seleção em função da relevância ao contexto proposto, foi realizada a leitura, na íntegra, das obras resultantes, sendo selecionadas 45 para compor a base de dados da pesquisa, conforme descrito no Quadro 1. 
Quadro 1 - Teses e Dissertações sobre Marketing Ambiental selecionadas por Títulos/Autores/Ano

\begin{tabular}{|c|c|}
\hline Títulos & Autores/Ano \\
\hline $\begin{array}{l}\text { "Marketing ambiental: desafio, tendência ou } \\
\text { utopia empresarial" }\end{array}$ & (TAGLIAFERRO, 2000a) \\
\hline "Marketing ecológico no Brasil" & (TAGLIAFERRO, 2000b) \\
\hline $\begin{array}{l}\text { "Integrando ação e comunicação para uma } \\
\text { estratégia de Marketing ambiental: o caso } \\
\text { Aracruz Celulose" }\end{array}$ & (OLIVEIRA; WAISSMAN, 2002) \\
\hline $\begin{array}{l}\text { "Motivações para o lançamento de um produto } \\
\text { ecologicamente correto: um estudo de caso" }\end{array}$ & (MOTTA, 2007) \\
\hline $\begin{array}{l}\text { "O marketing ecológico como vantagem } \\
\text { competitiva" }\end{array}$ & (MOTTA; OLIVEIRA, 2007) \\
\hline $\begin{array}{l}\text { "Marketing verde e o consumo consciente: um } \\
\text { estudo sobre o apelo ecológico de dois produtos" }\end{array}$ & (BAISCH, 2008) \\
\hline $\begin{array}{l}\text { "Competitividade baseada no marketing } \\
\text { ecológico" }\end{array}$ & (MOTTA, 2008) \\
\hline $\begin{array}{l}\text { "A contribuição do marketing socioambiental } \\
\text { nas organizações" }\end{array}$ & (LOPES et al., 2008) \\
\hline $\begin{array}{l}\text { "Análise da interação dos stakeholders na } \\
\text { adoção de estratégias de marketing verde: um } \\
\text { estudo em empresa moveleira" }\end{array}$ & (BRANDÃO, 2009) \\
\hline $\begin{array}{l}\text { "Marketing verde: responsabilidade social } \\
\text { e ambiental integradas na envolvente de } \\
\text { marketing" }\end{array}$ & (DALMORO et al., 2009) \\
\hline $\begin{array}{l}\text { "Marketing social corporativo - MSC e o } \\
\text { consumo consciente" }\end{array}$ & (FREITAS; REZENDE, 2010) \\
\hline $\begin{array}{l}\text { "A influência do marketing verde nos hábitos de } \\
\text { consumo dos jovens universitários dos cursos } \\
\text { de administração: um estudo em instituições de } \\
\text { ensino superior (IES)" }\end{array}$ & (PRADO et al., 2011) \\
\hline "A rotulagem ambiental no agronegócio" & $\begin{array}{c}\text { (PEREIRA; MANGUALDE, } \\
\text { 2011) }\end{array}$ \\
\hline $\begin{array}{l}\text { "A influência dos stakeholders na adoção de } \\
\text { estratégias de marketing verde" }\end{array}$ & (BRANDÃO et al., 2011) \\
\hline $\begin{array}{l}\text { "Produtos orgânicos: as ferramentas de } \\
\text { marketing para sua sustentabilidade econômica" }\end{array}$ & (GRAZIANO, 2011) \\
\hline $\begin{array}{l}\text { "Os hábitos de consumo das gerações Y e Z: a } \\
\text { dimensão ambiental nos contextos familiar e } \\
\text { escolar" }\end{array}$ & (SCHARF; OLIVEIRA, 2013) \\
\hline "Marketing verde e a propaganda ecológica" & (GUIMARÃES, 2012) \\
\hline
\end{tabular}




\begin{tabular}{|c|c|}
\hline Títulos & Autores/Ano \\
\hline $\begin{array}{l}\text { "A perspectiva responsável do marketing e o } \\
\text { consumo consciente: uma interação necessária } \\
\text { entre a empresa e o consumidor" }\end{array}$ & (SILVA et al., 2012) \\
\hline $\begin{array}{l}\text { "Impactos da consciência ecológica sobre } \\
\text { atitudes do consumidor diante de produtos e } \\
\text { marcas" }\end{array}$ & (MONTEIRO et al., 2012) \\
\hline $\begin{array}{l}\text { "A responsabilidade social empresarial e o } \\
\text { marketing: reflexos na atitude e na lealdade do } \\
\text { consumidor de supermercados em São Paulo/SP" }\end{array}$ & (MARIN; MORETTI, 2012) \\
\hline $\begin{array}{l}\text { "Going green: consumo sustentável e as } \\
\text { estratégias de marketing verde" }\end{array}$ & (TERRES; BRANCHI, 2012) \\
\hline $\begin{array}{l}\text { "Produtos orgânicos: um estudo sobre os } \\
\text { motivos que influenciam a decisão de compra } \\
\text { do consumidor na cidade do Rio de Janeiro" }\end{array}$ & (FARO, 2013) \\
\hline $\begin{array}{l}\text { "Estudo sobre a percepção do consumidor na } \\
\text { prática dos gestos de consumo como atitudes de } \\
\text { engajamento na preservação ambiental: estudo } \\
\text { de caso com estudantes da universidade Feevale" }\end{array}$ & (KLAIN, 2013) \\
\hline $\begin{array}{l}\text { "Comportamento de consumo verde: uma } \\
\text { análise dos consumidores de Campina Grande" }\end{array}$ & (RODRIGUES et al., 2014) \\
\hline $\begin{array}{l}\text { "Utilização de projetos de biocombustível como } \\
\text { fator de fortalecimento da imagem da marca } \\
\text { Petrobras" }\end{array}$ & (PEDRINI; PUPERI, 2014) \\
\hline $\begin{array}{l}\text { "Marketing verde e práticas socioambientais } \\
\text { nas indústrias do Paraná" }\end{array}$ & (LOPES; PACAGNAN, 2014) \\
\hline $\begin{array}{l}\text { "Análise do comportamento dos consumidores de } \\
\text { produtos ecologicamente corretos no município } \\
\text { de São Gabriel: o caso dos produtos orizícolas } \\
\text { certificados com selo ambiental do Irga" }\end{array}$ & (TRINDADE et al., 2014) \\
\hline $\begin{array}{l}\text { "Marketing verde aplicado à estratégia como } \\
\text { prática: análise de variáveis na visão de } \\
\text { empreendedores" }\end{array}$ & (VEIGA NETO et al., 2014) \\
\hline $\begin{array}{l}\text { “Marketing ambiental: o caso da associação } \\
\text { comercial e empresarial Alfa” }\end{array}$ & (BRITO Jr.; CASTRO, 2015) \\
\hline $\begin{array}{l}\text { "O marketing verde como fator de diferenciação } \\
\text { das empresas do lbovespa" }\end{array}$ & (ARAÚJO, 2015) \\
\hline $\begin{array}{l}\text { "Marketing ambiental nos postos de } \\
\text { combustíveis no município de São Gabriel-RS" }\end{array}$ & $\begin{array}{l}\text { (LEDERHOS; BARATA; ALVES, } \\
\text { 2015) }\end{array}$ \\
\hline $\begin{array}{l}\text { "Os desafios da consciência ambiental: o } \\
\text { marketing verde em questão" }\end{array}$ & (GUIMARÃES, 2015) \\
\hline
\end{tabular}




\begin{tabular}{|c|c|}
\hline Títulos & Autores/Ano \\
\hline $\begin{array}{l}\text { "A influência da comunicação de ações } \\
\text { sustentáveis corporativas na intenção de } \\
\text { compra e o efeito moderador do tipo de } \\
\text { consumidor" }\end{array}$ & (OLIVEIRA et al., 2015) \\
\hline $\begin{array}{l}\text { "Marketing verde como propensa vantagem } \\
\text { competitiva sustentável de uma organização" }\end{array}$ & (MOREIRA, 2016) \\
\hline $\begin{array}{l}\text { "A importância da responsabilidade } \\
\text { socioambiental e da logística de reserva como } \\
\text { estratégia competitiva para as empresas" }\end{array}$ & (GARCIA et al., 2016) \\
\hline $\begin{array}{l}\text { "Marketing sustentável e sustentabilidade: o } \\
\text { fator decisivo na aquisição de um produto de } \\
\text { cosmética" }\end{array}$ & (DIZ, 2016) \\
\hline $\begin{array}{l}\text { "A percepção ambiental dos consumidores } \\
\text { de hortaliças orgânicas da feira municipal de } \\
\text { Palotina-PR" }\end{array}$ & (ZANELLA, 2017) \\
\hline $\begin{array}{l}\text { "Prêmios de sustentabilidade como proposta de } \\
\text { marketing verde para instituições bancárias" }\end{array}$ & (DIAS, 2017) \\
\hline $\begin{array}{l}\text { "Análise da consciência ambiental e do } \\
\text { consumo verde em Portugal: factores } \\
\text { comprobatórios e perfil de consumidor verde" }\end{array}$ & (PEREIRA, 2017) \\
\hline "Marketing verde x maquiagem verde" & (MARTINS, 2018) \\
\hline $\begin{array}{l}\text { "Composto de marketing de varejo sustentável: } \\
\text { o caso King 55" }\end{array}$ & (SARTORETTO et al., 2018) \\
\hline $\begin{array}{l}\text { "Efeitos de instrução e presença de selo na } \\
\text { escolha entre produtos sustentáveis e não } \\
\text { sustentáveis" }\end{array}$ & (COELHO, 2018) \\
\hline $\begin{array}{l}\text { "Algumas pistas sobre o marketing ambiental } \\
\text { pelo olhar da psicossociologia" }\end{array}$ & (ALMEIDA, 2019) \\
\hline $\begin{array}{l}\text { "Comportamento do consumidor } \\
\text { ecologicamente consciente: Análise sob a ótica } \\
\text { do modelo de Straughan e Roberts" }\end{array}$ & (APPIO et al., 2019) \\
\hline $\begin{array}{l}\text { "Influência do marketing verde no surgimento } \\
\text { de restaurantes sustentáveis em Florianópolis" }\end{array}$ & (ROSA, 2019) \\
\hline
\end{tabular}

Fonte: Dados da pesquisa.

Os trabalhos supracitados apresentam os estudos sobre o marketing ambiental e seus benefícios diante da crise ambiental emergente em nosso contexto atual. Apontam as considerações mais relevantes quanto ao 
estado do conhecimento sobre o tema da pesquisa e suas contribuições perante os problemas ambientais da atualidade, o que possibilitou alcançar os objetivos propostos.

\section{RESULTADOS E DISCUSSÃO}

Entre os temas mais recorrentes encontrados na análise dos materiais sobre marketing ambiental, destacam-se como mais relevantes (Quadro 2):

Quadro 2 - Temas convergentes levantados no estado da arte sobre marketing ambiental

\begin{tabular}{|l|l|}
\hline \multicolumn{1}{|c|}{ Temas } & \multicolumn{1}{c|}{ Autores/ano } \\
\hline Alimentos orgânicos & Faro (2013), Panucci Filho et al. (2019) \\
\hline Camuflagem verde & Dias et al. (2017), Martins (2018) \\
\hline Certificação ambiental & $\begin{array}{l}\text { Trindade et al. (2014), Pedroso e Coelho } \\
\text { (2018) }\end{array}$ \\
\hline Comportamento verde & Pereira (2017) \\
\hline Comunicação eficaz & $\begin{array}{l}\text { Oliveira e Waissman (2002), Guimarães } \\
\text { (2012), Satoretto et al. (2018) }\end{array}$ \\
\hline $\begin{array}{l}\text { Conceitos sobre o marketing } \\
\text { ambiental }\end{array}$ & $\begin{array}{l}\text { Tagliaferro (2000a), Oliveira e Waisman } \\
\text { (2002), Araújo (2014), Dias et al. (2017) }\end{array}$ \\
\hline $\begin{array}{l}\text { Consciência ambiental dos } \\
\text { stakeholders de uma empresa }\end{array}$ & Oliveira e Waissman (2002), Brandão (2009) \\
\hline Consumerismo & Tagliaferro (2000b), Rosa (2019) \\
\hline Consumo consciente & $\begin{array}{l}\text { Tagliaferro (2000b), Baisch (2008), Trindade } \\
\text { et al. (2014) }\end{array}$ \\
\hline $\begin{array}{l}\text { Credibilidade gerada pelo } \\
\text { marketing ambiental }\end{array}$ & Guimarães, Viana e Costa (2015) \\
\hline Desenvolvimento sustentável & Diz (2019) \\
\hline Ecosofia & Almeida (2019) \\
\hline $\begin{array}{l}\text { Ganhos empresariais com } \\
\text { o empenho de tornarem-se } \\
\text { "verdes" }\end{array}$ & Tagliaferro (2000b), Rosa (2019) \\
\hline Gestão socioambiental & Lopes e Pacagnan (2014) \\
\hline $\begin{array}{l}\text { Logística de reserva } \\
\text { Motivações da adoção de ma- } \\
\text { rketing verde }\end{array}$ & Garcia et al. (2016) \\
\hline
\end{tabular}




\begin{tabular}{|l|l|}
\hline \multicolumn{1}{|c|}{ Temas } & \multicolumn{1}{c|}{ Autores/ano } \\
\hline Perfil do consumidor & $\begin{array}{l}\text { Tagliaferro (2000a), Klain (2013), Trindade et } \\
\text { al. (2014), Pereira (2017), Panucci Filho et al. } \\
(2019)\end{array}$ \\
\hline Rizoma verde & Almeida (2019) \\
\hline Rotulagem verde & $\begin{array}{l}\text { Pereira (2017), Martins (2018), Satoretto et } \\
\text { al. (2018) }\end{array}$ \\
\hline Vantagem competitiva & $\begin{array}{l}\text { Moreira (2016), Garcia et al. (2016), Diz } \\
\text { (2016) }\end{array}$ \\
\hline
\end{tabular}

Fonte: Dados da pesquisa.

Tagliaferro (2000a), em seu projeto "Marketing ambiental: desafio, tendência ou utopia empresarial", apresentou uma pesquisa descritiva que explorava as principais tendências sobre marketing ambiental e marketing ecológico que se tinha até aquele presente momento, com foco em causar uma reflexão nas empresas sobre o uso de estratégias e táticas ambientais responsáveis. O autor demonstra em sua pesquisa as vantagens do marketing ambiental sobre o convencional, deixando claro que não se trata apenas de rotulagens ou dizer-se ecologicamente correto, trata-se de uma mudança de paradigma em fazer e pensar na preservação como princípio fundamental para o equilíbrio do planeta, e na postura dos consumidores em reconhecerem e optarem por produtos "verdes".

Já com o artigo "Marketing ecológico no Brasil?", Tagliaferro (2000b) apresentou um alerta às organizações nacionais sobre como atingir os consumidores que estão preocupados com o consumo consciente e a preservação ambiental por meio do marketing ambiental, demonstrando em sua pesquisa que o Brasil tende a adotar o marketing ambiental em grande escala, assim como já era feito em outros países, por meio de um aculturamento da sociedade diante dos problemas ambientais que estavam tomando proporções cada vez maiores.

Oliveira e Waissman (2002) apresentam como emergiu o conceito de marketing ambiental e sua importância para consolidar a marca de uma empresa por meio de melhorias socioambientais e, principalmente, com uma comunicação eficaz entre seus stakeholders. Demonstra-nos em seus 
estudos que a vantagem competitiva pode ser estabelecida por meio da comunicação, quando as ferramentas são utilizadas com eficiência para construir uma reputação positiva da marca de uma empresa. A qualidade dos produtos, aliada aos serviços prestados, em conjunto com táticas ambientais sustentáveis, é de fundamental importância para que uma empresa possa usar da boa comunicação e/ou marketing ambiental para o aumento de sua lucratividade e preferência por sua marca em detrimento das demais que prestam os mesmos serviços. "Avaliamos que não basta à empresa falar bem de si mesma, coube que ela usasse a presença de formadores de opinião para testemunhar suas ações, visto que sua credibilidade ao falar de si própria não alcançava os objetivos desejados" (OLIVEIRA; WAISSMAN, 2002, p. 21).

Com Baisch (2008), em "Marketing verde e o consumo consciente: um estudo sobre o apelo ecológico de dois produtos", tem-se um estudo do comportamento dos consumidores diante do marketing verde ou consumo consciente, buscando identificar os grupos de consumidores em relação a produtos com apelos ecológicos, especificamente tratando de dois produtos em questão: creme hidratante com extratos naturais, destinado ao público feminino; e pneus reciclados ou remodelados, destinados ao público masculino. Nota-se que o interesse maior pelo apelo ecológico é por parte do público feminino ou por produtos que sejam diretamente ligados ao consumo pessoal.

Brandão (2009) apresentou seus estudos a respeito da forma como os stakeholders influenciam na adoção de estratégias de marketing verde sob a ótica das empresas.

Diz que várias organizações têm sofrido pressões de diferentes grupos para mudar seu comportamento ambiental e relaciona cinco possíveis razões para as atividades de marketing ambiental nas empresas: 1 . A imposição legal - a força da legislação ambiental; 2. Oportunidade de usar o marketing ambiental para alcançar objetivos das organizações; 3. As organizações acreditam ter uma obrigação moral de ser socialmente responsável; 4. As atividades ambientais da concorrência pressionam mudanças de comportamento das organizações; 5. Reengenharia dos processos produtivos e dos produtos para minimizar os custos associados ao desperdício (POLONSKY, 1995 apud BRANDÃO, 2009, p. 36-37). 
A unidade de análise da pesquisa de Brandão, uma empresa moveleira, revelou que a preocupação ambiental é um fator presente na consciência moral dos seus stakeholders, "mas a iniciativa de produzir verde só surgiu a partir das imposições legais através dos órgãos governamentais e da falta de matéria-prima disponível no mercado" (BRANDÃO, 2009, p. 76).

Guimarães (2012) retratou a rápida modificação do ambiente competitivo das empresas nos últimos tempos, quanto aos aspectos culturais, sociais, políticos e econômicos da sociedade, tendo as empresas a necessidade de se adaptarem de modo a satisfazer as necessidades dos consumidores do século XXI. O autor sintetizou a demanda dos profissionais de marketing da seguinte forma:

Um maior número de profissionais de marketing está concentrando sua atenção no "segmento ecológico" da população. Papel, plástico e alumínio reciclados, produtos livres de ozônio e com baixos teores de enxofre, são tipos de produtos posicionados com base no apelo ambiental (GUIMARÃES, 2012, p. 3).

Assim, as empresas devem ser responsáveis pela divulgação, na mídia, das características ecológicas de seus produtos, orientando adequadamente os consumidores em relação aos aspectos ecológicos dos produtos que comercializam.

Com Faro (2013), tem-se uma pesquisa que revelou os fatores que influenciam o comportamento de compra dos consumidores de produtos orgânicos nas feiras livres e lojas especializadas da cidade do Rio de Janeiro. Severo e Pedrozo (2008 apud FARO, 2013) afirmam que, para se habilitar nesse mercado de orgânicos, os produtores precisam respeitar as normas de produção orgânica em todas as fases de plantio, desde a preparação do solo até a embalagem do alimento, de forma a preservar os recursos naturais, pois, além de existir um conjunto de procedimentos a serem seguidos pelos agricultores que optam pela produção orgânica, eles devem buscar uma espécie de ética orgânica, calcada em "princípios, tais como entender a terra como uma fonte de vida, priorizar alimentar mais o solo do que a planta, utilizar sistemas diversificados de produção, buscar a independência do agricultor, a valorização da saúde e, finalmente, respeitar a natureza" (FARO, 2013, p. 21). 
Foi possível notar que os atributos do produto orgânico que mais influenciam a decisão de compra são, em primeiro lugar, a isenção de agrotóxicos; em segundo lugar, os benefícios à saúde do consumidor e de sua família; em terceiro lugar, a preservação do meio ambiente; em quarto lugar, o maior valor nutricional e, em quinto lugar, a valorização da agricultura familiar. Ainda de acordo com as respostas obtidas nas entrevistas de campo, fatores dos produtos orgânicos como melhor sabor, proteção das gerações futuras e sua certificação ambiental, também são significativos, mas ocorrem em uma escala de importância secundária (FARO, 2013, p. 96).

Com Klain (2013), foi analisado o nível de conscientização para a transformação dos gestos de consumo em atitudes de engajamento na preservação ambiental e a influência do marketing verde sobre os jovens consumidores universitários, em relação ao seu consumo consciente, avaliando sua percepção na compra de produtos e serviços que percebem como comprometidos com a preservação ambiental e a ecologia. A autora destaca que:

Muito se discute sobre o tema, mas poucas empresas investem de maneira significativa em marketing verde incentivando e convencendo os consumidores de que o comportamento de cada um deles vai fazer a diferença em relação ao meio ambiente, para que eles passem definitivamente a considerar isso no momento de suas compras, além de trabalhar para que cada vez mais aumente o número de consumidores verdes (KLAIN, 2013, p. 77).

Com a pesquisa, foi possível analisar a relação existente entre a consciência ecológica dos jovens universitários com o consumo consciente, verificando aspectos como as implicações e o impacto socioambiental que as suas condutas provocam em suas vidas e no meio ambiente.

Martins (2018) apresenta um estudo sobre o "marketing verde" e a "maquiagem verde", ou seja, empresas que usam do marketing ambiental para vender produtos que não seguem os padrões necessários para serem considerados sustentáveis e, assim, acabam por prejudicar as empresas que primam pela sustentabilidade e têm ética em suas ações.

O conceito de Marketing Verde vem do estado consciente de se fazer opções de consumo, a ideia tem sido despertada em diversas organizações, por uma pressão do consumidor, que está disposto, inclusive, a pagar mais caro para ter o selo verde no produto que consome e ter a certeza do processo de rastreabilidade (para saber se utilizou mão de obra escrava, infantil ou como aquele produto foi fabricado), estreitando a relação entre produto e consumidor (MARTINS, 2018, p. 2). 
Apesar das tentativas em ludibriar os consumidores, estes estão preparados a lidar com as propagandas enganosas e sabem distinguir entre um produto de origem verde e um produto que apenas se rotula como verde.

Ao concluir as análises sobre o estado do conhecimento do marketing ambiental, foi possível apontar as possibilidades para o apelo dessa estratégia em função de alcançar uma vida sustentável no século atual.

\section{CONSIDERAÇÕES FINAIS}

Ao concluir as análises sobre o estado da arte do marketing ambiental e/ou marketing verde, foi possível identificar as possibilidades do uso dessa estratégia de marketing para aumentar as vendas e valorizar a marca das empresas que tratam da preservação ambiental diante da crise ambiental que se estabelece pelo mundo.

Respondendo ao questionamento de partida da pesquisa, este artigo propôs um alerta às questões de degradações ambientais atuais, apontando o marketing ambiental no Brasil como alternativa promissora em regularizar o desequilíbrio causado pela própria sociedade.

Cabe ressaltar a importância dos consumidores nos processos de reciclagem e aquisição dos produtos verdes, sendo eles os principais agentes para que esse ciclo, de fato, seja efetivo e funcional.

Muitos autores descreveram sobre a importância do marketing ambiental e os critérios para que os produtos possam ser identificados como "verdes", o que ajudou a conhecer algumas características dos consumidores desses produtos sustentáveis.

O perfil das pesquisas abordadas utilizou diferentes amostras de projetos para compreensão de todas as vertentes que envolveram os consumidores e as empresas engajadas com a sustentabilidade.

Almeja-se, com esta proposta, oferecer suporte teórico e prático para interessados na área de Gestão de Marketing, evidenciando o quanto suas contribuições, voltadas a uma ótica sustentável, podem fazer a diferença para os consumidores e para o meio ambiente, favorecendo a preservação, o equilíbrio sustentável, o emprego para muitas pessoas e também para sua sólida e crescente rentabilidade. 
De forma a representar um campo de estudos que se torna cada vez mais amplo, os saberes sobre marketing ambiental e as investigações mais aprofundadas sobre o perfil dos consumidores são de grande relevância para fundamentar quaisquer novas hipóteses e conceitos sobre a composição de estratégias de um futuro mais saudável.

\section{REFERÊNCIAS}

ANDRADE, J. N. S. Consumidor verde: uma avaliação do perfil dos consumidores. 2012. Dissertação (Mestrado em Administração) - Universidade Federal Rural do Rio de Janeiro, Seropédica, RJ, 2012.

BAISCH, L. B. Marketing verde e o consumo consciente: um estudo sobre o apelo ecológico de dois produtos. 2008. Dissertação (Mestrado em Administração) - Pontifícia Universidade Católica do Rio de Janeiro, Rio de Janeiro, RJ, 2008. Disponível em: https://www.maxwell.vrac.puc-rio.br/colecao.php?strSecao=resu Itado\&nrSeq=13924@1. Acesso em: 29 dez. 2019.

BAROTO, A. Marketing verde. Paraná, 2007. Disponível em: http://www.uesc.br/ revistas/ calea/edicoes/rev4_artigo7.pdf Acesso em: 20 jun. 2019.

BARTIAUX, F. Greening some consumption behaviours: do new routines require agency and reflexivity? In: ZACCAI, E. (Ed.). Sustainable consumption, ecology and fair trade. United States/UK: Taylor\&Francis Publishers, 2007. p. 91-108. Disponível em: https://www.researchgate.net/publication/269873786_Greening_some_ consumption_behaviours do_new_routines_require_agency_and_reflexivity/ citation/download. Acesso em: 28 dez. 2019.

BENTON, Raymond. Environmental knowledge and attitudes of family: business versus arts and sciences. Journal of Education for Business, p. 12-16, set./out. 1994.

BLAIR, I. Greener products. In: CHARTER, Martin. Greener marketing: a responsible approach to business. Sheffield: Greenleaf, 1992. Disponível em: http://hdl. handle. net/10183/3904. Acesso em: 14 dez. 2019.

BRANDÃO, M. R. M. Análise da interação dos stakeholders na adoção e estratégias de marketing verde: um estudo em empresa moveleira. 95f. 2009. Tese (Mestrado em Ciências em Engenharia de Produção) - Universidade Federal do Rio Grande do Norte, Natal, RN, 2009. Disponível em: http://www.livrosgratis.com.br/ download_livro_82641/analise_da_interacao_dos_stakeholders_na_adocao_de_ 
estrategias_de_marketing_verde-_um_estudo_em_empresa_moveleira. Acesso em: 5 jan. 2020.

CADORE, P. S. Marketing verde na atualidade. A Folha, Torres, jul. 2017. Disponível em: https://afolhatorres.com.br/colunas/o-marketing-verde-na-atualidade/. Acesso em: 20 ago. 2019.

CALOMARDE, J. V. Marketing ecológico. Madrid: Piramide, 2000.

CAMINO, R. J. Re-evaluating green marketing strategy: a stakeholder perspective. European Journal of marketing. v. 41, n. 11-12, p. 1328-58, 2006.

CONSELHO NACIONAL DE AUTORREGULAMENTAÇÃO PUBLICITÁRIA. Disposições legais de publicidade. Portal do CONAR, 2018. Disponível em: http://www.conar. org.br/. Acesso em: 10 maio 2019.

DONAIRE, D. Gestão Ambiental na empresa. São Paulo: Atlas, 1999.

ECYCLE. Greenwashing: entenda o que é e evite. eCycle, 2019. Disponível em: https://www.ecycle.com.br/2094-greenwashing. Acesso em: 20 jul. 2019.

ENOKI, P. A.; ADUM, S. H. N.; FERREIRA, M. Z.; VALDEVINO, S. L.; AURELIANO, C. A.; SILVA, A. A. Estratégias de marketing verde na percepção de compra dos consumidores na grande São Paulo. In: ENCONTRO DE MARKETING DA ASSOCIAÇÃO NACIONAL DE PÓS-GRADUAÇÃO E PESQUISA EM ADMINISTRAÇÃO- EMA, 3., 2008, Curitiba. Anais [...]. Curitiba, 2008.

FARO, P. L. D. Produtos orgânicos: um estudo sobre os motivos que influenciam a decisão de compra do consumidor na cidade do Rio de Janeiro. 2013. Dissertação (Mestrado em Administração) - Pontifícia Universidade Católica do Rio de Janeiro, Rio de Janeiro, RJ, 2013.

FERREIRA, N. S. A. As pesquisas denominadas "estado da arte". Revista Educação \& Sociedade, Campinas, n. 79, p. 257-72, ago. 2002.

FULLER, D. A.; OTTMAN, J. A. Moderating unintended pollution: the role of sustainable product design. Journal of Business Research, v. 57, n. 11, p. 1231-8, nov. 2004.

GARCIA, R. D.; MORAES; C. C.; PAVANELI; K. F.; SCATENA JUNIOR, S. A. A importância da responsabilidade socioambiental e da logística de reserva como estratégia 
competitiva para as empresas. Revista Eletrônica Organizações e Sociedade, Iturama, v. 5, n. 3, 2016. Disponível em: http://revista.facfama.edu.br/index.php/ ROS/article/view/133. Acesso em: 10 mar. 2020.

GUIMARÃES, A. F. Marketing verde e a propaganda ecológica. 2012. Dissertação (Mestrado em Administração)- Pontifícia Universidade Católica do Rio de Janeiro, Rio de Janeiro, RJ, 2012. Disponível em: http://comciencia.scielo.br/scielo.php?s cript=sciarttext\&pid=S1519-76542012 000200010\&lng=e\&nrm=iso. Acesso em: 6 jan. 2020.

KLAIN, S. T. Estudo sobre a percepção do consumidor na prática dos gestos de consumo como atitudes de engajamento na preservação ambiental: estudo de caso com estudantes da universidade Feevale. EcoDebate, dez. 2013. Disponível em: . Acesso em: 9 jan. 2020.

KOTLER, P. Marketing para o Século XXI. São Paulo: Futura, 2002.

MARTINS, W. Marketing verde x maquiagem verde. Marketeiro Confesso, set. 2018. Disponível em: . Acesso em: 30 dez. 2019.

MOTTA, S. L. S.; OLIVEIRA, B. A. C. O marketing ecológico como vantagem competitiva. Rege-Revista de Gestão USP, v. 14, p. 49-59, 2007.

OLIVEIRA, J. A. P.; WAISSMAN, V. Integrando ação e comunicação para uma estratégia de marketing ambiental: o caso Aracruz Celulose. REAd, Rio de Janeiro, v. 8, n. 6, Edição Especial 30, nov./dez. 2002.

OTTMAN, J. A. Marketing verde: desafios e oportunidades para a nova era do marketing. 1. ed. São Paulo: Makron Books Ltda., 1994. p. 18-44.

PEATTIE, K. Green marketing. London: Pitman Publishing, 2005.

POLONSKY, M. J. An introduction to green marketing. Electronic Green Journal, v. 1, n. 2, nov. 1994.

POLONSKY, M. J.; OTTMAN, J. A. Ecological Imperatives and the Role of Marketing. In: ALMA, M. A.; MINTU-WIMSATT T. (Ed.). Environmental Marketing: strategies practice, theory and research. New York: Haworth Press, 1998.

PRAKASH, A. Greening the firm: the politics of corporate environmentalism. Cambridge University Press: Cambridge, 2002. 
PUJARI, D.; WRIGHT, G.; PEATTIE, K. Verde e competitivo: influências no desempenho ambiental de desenvolvimento de novos produtos. Journal of Business Research, $\mathrm{v}$. 56, 657-71, 2003. Doi: https://doi.org/ 10.1016/S0148-2963(01)00310-1.

RAFAEL, R. R. Marketing verde - uma análise multimodal da construção do discurso da sustentabilidade em campanhas publicitárias empresariais. 2013. Dissertação (Mestrado em Administração) - UFU - Universidade Federal de Uberlândia, Uberlândia, MG, 2013. Disponível em: http://repositorio.unb.br/ bitstream/10482/13721/1/2013_Ricardo \%20dosReisRafael.pdf. Acesso em: 10 ago. 2019.

RESENDE, V. M.; RAMALHO, V. Análise de discurso crítica. São Paulo: Contexto, 2006, 2009.

REX, E.; BAUMANN, H. Beyond ecolabels: what green marketing can learn from conventional marketing. Journal of Cleaner Production, v. 15, n. 6, p. 567-76, 2007.

SOUZA, G. K. A. Poluentes emergentes e sua ameaça à efetivação da sustentabilidade. 2018. Dissertação (Pós Graduação em gestão Ambiental) - Universidade de Franca - Polo Uberaba/MG. Uberaba/MG, RJ, 2018.Disponível em: file://C:/Users/User/ Downloads/ DISSERTA\%C3 \%87\% C3\%830\% 20DA\%20GREYCE!!!\%20_para\%20 Banca.pdf. Acesso em: 15 jun. 2019.

STECKERT, C.; BRIDI, E. Marketing verde: a adoção de uma postura ambiental. Florianópolis: Agathos, 2005. Disponível em: www.agathos.assevim.edu. br/1edicao/. Acesso em: 25 maio 2019.

TAGLIAFERRO, E. R. Marketing ambiental: desafio, tendência ou utopia empresarial. 2000. Monografia (Pós-Graduação em Gestão Ambiental)- Centro Universitário do Norte Paulista (Unorp), São José do Rio Preto, SP, 2000a.

TAGLIAFERRO, E. R. Marketing Ecológico no Brasil? In: SEMINÁRIO INTERNACIONAL: GESTÃO EMPRESARIAL E COMÉRCIO INTERNACIONAL. Uma Perspectiva Globalizada, 1., São José do Rio Preto, 2000. Anais [...]. São José do Rio Preto: Unorp, 2000b.

TEISL, M. F.; NOBLET, C. L.; RUBIN, J. O projeto de um programa de eco-marketing e rotulagem para veículos no Maine. In: GROTE U., BASU A. K., CHAU N. H. (Ed.). Novas fronteiras na rotulagem ambiental e social. Rio de Janeiro, RJ, 2007. p. 11-35.

VARADARAJAN, P. R. Marketing Ecológico. 2000. Dissertação (Pós-Graduação em Marketing)- Pontifícia Universidade Católica do Rio de Janeiro, Rio de Janeiro, RJ, 
Carlos Alberto MENEZES; Evandro Roberto TAGLIAFERRO; João Alberto CAMPATO JÚNIOR;

Roberto ANDREANI JÚNIOR

2000. Disponível em: . Acesso em: 2 jan. 2020.

WAGNER, S. A. Understanding green consumer behavior: a qualitative cognitive approach. New York: Haworth Press, 1998

WASIK, John F. Green marketing and management: a global perspective. Massachusetts: Blackwell, 1996. 